\title{
A Displacement-Based Theory for Predicting the Support Force on the Shield Tunneling Surface in Sandy Soil Layers
}

\author{
Guang Sun, ${ }^{1}$ Han Liu, ${ }^{1}$ Zhiyuan Guo, ${ }^{2}$ Ranjie $\mathrm{Li}^{2}$ and Tao Li ${ }^{2}{ }^{2}$ \\ ${ }^{1}$ Hebei Research Institute of Construction and Geotechnical Investigation Co. Ltd., Shijiazhuang 050031, China \\ ${ }^{2}$ School of Civil Engineering, Beijing Jiaotong University, Beijing 100044, China \\ Correspondence should be addressed to Tao Li; taoli-bj@bjtu.edu.cn
}

Received 19 March 2021; Revised 6 April 2021; Accepted 8 April 2021; Published 20 April 2021

Academic Editor: Faming Huang

Copyright (c) 2021 Guang Sun et al. This is an open access article distributed under the Creative Commons Attribution License, which permits unrestricted use, distribution, and reproduction in any medium, provided the original work is properly cited.

Due to the poor stability of the loose sandy soil layer, if the support force is not properly controlled during the construction process of the shield tunnel using the earth pressure balance method, it is easy to cause the ground to collapse or uplift. Therefore, understanding the support force of the excavation surface of shield tunneling in sandy soil layer is very vital to ensure the stability of the excavation surface. Firstly, it is assumed that the damaged soil is a three-dimensional wedge and a modified three-dimensional wedge in the active and passive failure modes, respectively. The shallow soil pressure theory and the soil plastic limit equilibrium theory are derived by analyzing the stress distribution on the damaged soil. The equation for revealing the inner essence between the support force of the shield excavation surface and excavation surface displacement under the condition of sand-covered soil is used. Secondly, the numerical simulation method analyzes the displacement of the excavation surface when the support force changes under different working conditions, and the relationship curve between the excavation surface support force and the shield tunneling displacement is obtained. The comparison and analysis between the numerical simulation calculation and the theoretical analysis indicate that the deduced calculation equation for the excavation surface support force based on the displacement earth pressure is reasonable.

\section{Introduction}

With the acceleration of China's urbanization process and the increasing urban population, the subway has become the first choice to relieve traffic pressure and promote urban development. Shield tunneling is extensively utilized in subway construction owing to its advantages of small environmental impact $[1,2]$ and a high degree of automation. The earth pressure balance shield is widely used because of the advantages of minor site impact and low cost. The support force required to ensure the excavation surface's stability for shield tunneling is an urgent problem to be solved. When the support force is too large, it may lead to the front soil uplift. When the support force is insignificant, it may lead to soil collapse. When shield tunneling is carried out in the sandy soil layer, the slag is not easy to be discharged, the cutter is seriously worn, and the equipment load is large. Simultaneously, sand is an extremely unstable soil layer, and its cohesion is minimal, which is easy to cause ground collapse. Therefore, the research on the support force on shield excavation surface in sandy soil layer has important engineering application value in reducing soil instability, controlling construction risk, and reducing construction cost.

Many theories have been made on the support force of the shield excavation surface, which have formed a variety of analysis methods such as the limit analysis method, and plastic balance theory, even considering the grouting reinforcement effect [3], drainage condition [4-6], migration of soil particles caused by infiltration $[7,8]$, and consolidation deformation caused by temperature disturbance during excavation [9-11]. The upper limit value of the active limit earth pressure of the shield excavation surface was usually used to analyze the double logarithm spiral model. Lee and Nam $[12,13]$ obtained the upper limit value of the excavation surface's support force under the condition of groundwater seepage in view of the upper limit theorem while the 
infiltration problem and its effect become a hot topic $[6,14]$. Soubri and Wong [15] assume that the soil's sliding surface before the construction excavation surface can be considered as a given logarithmic spiral surface and studied the maximum support force by the limit analysis method.

In the limit equilibrium method, the soil's sliding surface located before the excavation surface is assumed first, and then the solution is obtained by the equilibrium of each isolation body in the sliding surface. There are many models using limit equilibrium theory, and the three-dimensional wedge model is the most widely used. Vermeer et al. [16] assumed that the failure surface was a two-dimensional semicircle, a quarter circle, or a three-dimensional sphere and calculated the support force of the excavation surface according to the limit equilibrium method. Some scholars $[15,17]$ modified the threedimensional wedge model and revised the prism form above the wedge body to a trapezoid. The calculated results are closer to the centrifugal experiment results, but the effect of groundwater is not considered. Dai et al. [18] thought that the buried depth ratio manifests a noticeable action on the excavation surface instability of a tunnel and, therefore, improved the so-called "wedge-prism" limit equilibrium model.

Liang et al. [19] used the finite difference calculation software FLAC3D in a numerical simulation to analyze the shield excavation surface stability in the sandy soil layer and obtained the soil failure mechanism in front of the excavation surface. Mi and Xiang [20] explored the support force of the excavation surface by considering the seepage action in simulating shield construction. Some results show that groundwater is an essential factor affecting the force applied on ground structure, and generally, the support force becomes large when there exists groundwater in the soil layer. Liang et al. [21] numerically investigated the limit support pressure, mode of limit failure, inherit of instability, and failure pattern of the excavation surface in the loose granular stratum. Besides, similar researches also explored the induced pore water pressure in a saturated loose granular stratum during the construction of a shield tunnel using a coupled water-solid finite element model. Many scholars have studied the coupling effect of multiple physical fields to consider the influence of various complex factors on soil stress, such as the loadingunloading effect, seepage force, and the environmental temperature change caused by seasonal variation or in the process of excavation $[22,23]$ and established relevant constitutive laws as well as the soil particle movement models by seepage [24-26]. Overall, the existing research shows that there is rarely a complete calculation theory of excavation surface support force based on displacement evolution.

In view of the concept of displacement earth pressure and the plastic limit equilibrium theory of soil, this paper deduces the theoretical equation between the support force and the displacement of shield excavation surface under the shallow sandy soil layer's condition. A numerical simulation method is then utilized to reveal the displacement of the excavation surface when the support force changes under different working conditions. The relationship curve between the support force and the corresponding displacement (i.e., deformation) of the excavation surface is deduced, and the equations are analyzed. The results are helpful to understand the relationship between the induced displacement and the corresponding support force and to guide the selection of the suitable support force.

\section{Displacement Earth Pressure Theory}

Actually, the theory of displacement earth pressure means that there is a close association between the earth pressure (i.e., the stress in soil) and the induced displacement during the movement of the retaining structure, which also involves the coupling process of external force, seepage action [27, 28], soil microstructure damage [7, 29], and even thermal loading $[23,30]$. In the existing theory, the relationship between displacement and earth pressure is generally described from three aspects: (a) the displacement earth pressure curve is fitted according to the experimental data to obtain a certain functional relationship between earth pressure and displacement [31]; (b) the association between the internal friction angle and the displacement is obtained from the backfilling of retaining structure, to obtain the variation of earth pressure with the corresponding displacement; (c) in view of the stress-strain constitutive law of the soil behind the retaining structure, the calculation model of the relationship between displacement and earth pressure is established.

Terzaghi [32] carried out experimental research on the soil layer behind the retaining structure and acquired the relationship curve of earth pressure and corresponding displacement when the retaining structure moved. According to this theory, the soil takes on a static state at the beginning. Due to the external disturbance and the change of soil microstructure [29, 30], a certain deformation occurs. The deformation can be close to the structure or far away from the structure. At this time, the soil stress increases or decreases until the active/passive limit equilibrium state is reached. At this time, the soil pressure does not change, but the deformation can continue to change.

In the light of the theory of displacement earth pressure, it is clear that the earth pressure of the retaining structure changes with its displacement. When the retaining structure moves in the direction of filling, the earth pressure increases, and it decreases when it moves away from the soil until the deformation of the soil body achieves the limit state. The retaining structure is defined as the nonlimit state from an initial static state to a continuous sliding surface (reaching limit state).

The displacement ratio is defined to describe the nonlimit state of shield tunneling as follows:

$$
\begin{array}{r}
W=\frac{S}{S_{a}}, \\
\text { or } W=\frac{S}{S_{p}},
\end{array}
$$

where $S$ is the displacement of excavation, $S_{a}$ is the displacement when reaching the active limit state, and $S_{p}$ is the displacement when reaching the passive limit state.

When the internal friction angle $\left(\varphi_{m}\right)$ and external friction angle $\left(\delta_{m}\right)$ reach the maximum values of $\varphi$ and $\delta$ with the change of displacement, the soil reaches the failure 
limit state. It is assumed that there is a linear relationship between the induced displacement and the internal friction angle (or external friction angle). As indicated in Figure 1, the general relationship between $\varphi_{m}$ and $\delta_{m}$ and displacement ratio can be established.

It is evident from Figure 1 that when the retaining structure is at rest, $S=0, \varphi_{m}=\varphi_{0}, \delta_{m}=\delta_{0}$; when the displacement of the retaining structure reaches the limit displacement, that is, $S \geq S_{a}\left(S_{p}\right), \varphi_{m}=\varphi, \delta_{m}=\delta$.

When $0 \leq S \leq S_{a}\left(S_{p}\right)$, the calculation equations of $\varphi_{m}$ and $\delta_{m}$ are written as follows, respectively:

$$
\begin{aligned}
\tan \varphi_{m} & =\tan \varphi_{0}+K_{d}\left(\tan \varphi-\tan \varphi_{0}\right), \\
\tan \delta_{m} & =\tan \delta_{0}+K_{d}\left(\tan \delta-\tan \delta_{0}\right), \\
K_{d} & =\frac{4 \arctan \left(S / S_{a}\left(S_{p}\right)\right)}{\pi}=\frac{4 \arctan W}{\pi} .
\end{aligned}
$$

From the above equations that when in the static state, $S=0$, displacement ratio $W=0, K_{d}=0$; when in the limit state, $S=S_{a}\left(\right.$ or $\left.S_{p}\right)$, displacement ratio $W=1, K_{d}=1$. When the action of the initial external friction angle $\left(\delta_{0}\right)$ of the retaining structure is not considered, the initial internal friction angle $\left(\varphi_{0}\right)$ is simply expressed as

$$
\varphi_{0}=\arctan \left(\frac{\left(1-K_{0}\right)}{\left(1+K_{0}\right)}\right)
$$

where $K_{0}$ is the static earth pressure coefficient, namely, $K_{0}=1-\sin \varphi$.

When considering the influence of the initial internal friction angle $\left(\delta_{0}\right)$ of retaining structure, Chang [33] suggested a modified Coulomb earth pressure coefficient equation to obtain the following equation:

$$
\frac{1}{K_{0}}=\left[\frac{1}{\cos \varphi_{0}}+\sqrt{\tan ^{2} \varphi_{0}+\tan \varphi_{0} \tan \delta_{0}}\right],
$$

where $\delta_{0}$ is generally taken as $\varphi_{0} / 2$.

\section{Theory of Support Force on Shield Excavation Surface}

3.1. Basic Assumptions. Because the interaction between the shield and excavation surface is very complex in practical engineering $[17,33,34]$, the problem is simplified to facilitate mathematical derivation. It is assumed that (a) when the displacement of the center location of the excavation surface changes as a result of the change of support force, it is considered that the soil has wedge-shaped sliding and developed to the top of the shield; (b) in view of the existence of soil arch effect, the soil sliding is gradually developing upward; (c) the sandy soil layer is uniform and isotropic ideal rigid-plastic material, which obeys the so-called Mohr-Coulomb yield criterion; (d) the shape of the excavation surface is rectangular, and its area is equivalent to the area of the excavation surface, and the height of the rectangle is equivalent to the diameter $D$ of the excavation tunnel; (e) the seepage problem in the soil layer and the influence of hydrostatic pressure [35-37] are not

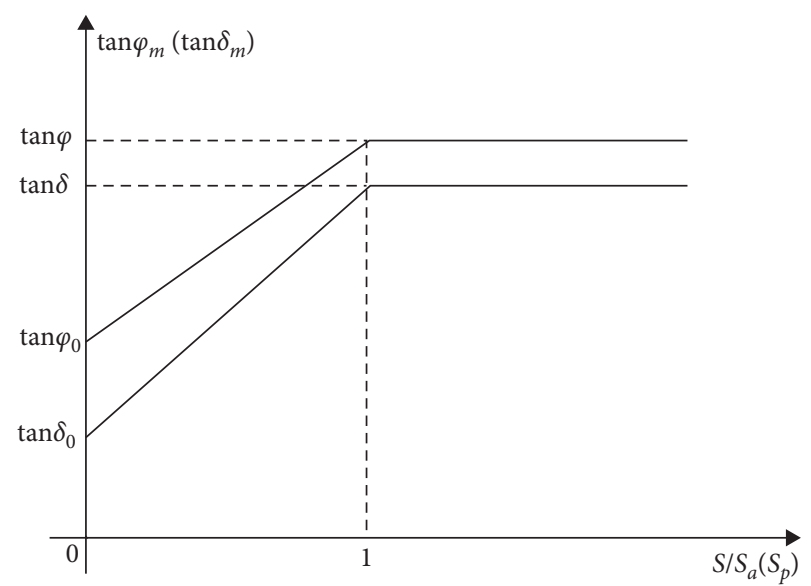

Figure 1: The evolution of internal friction angle with displacement.

considered due to the complexity of the interfering factors such as groundwater, ambient temperature, and even the existence of gas phase in unsaturated soil.

3.2. Calculation of Active Support Force of Excavation Surface. Based on the three-dimensional wedge model composed of two parts, this section deduces the equation of excavation surface support force owing to the concept of displacementbased earth pressure. Thus, the stress analysis mode of the wedge is shown in Figure 2.

According to the basic assumption, the area of the middle surface $(a b c d)$ of the discussed wedge is equal to the area of the circular excavation surface, and the height $(a d)$ is equivalent to the diameter $(D)$ of the construction tunnel. Let $B$ be the width of the rectangle $(a b c d)$; then,

$$
\mathrm{BD}=\frac{\pi D^{2}}{4} \text {. }
$$

If the perimeter of the rectangle ( $c d e f$ ) on the top of the wedge is $U$ and the area is $A$, and the angle of the inclined plane (abef) of the wedge (abcdef) is $\alpha$, then there is

$$
\frac{U}{A}=\frac{2(B+D \cot \alpha)}{B D \cot \alpha}
$$

Substituting equation (6) into equation (7), we obtain

$$
\frac{U}{A}=\frac{2}{D}\left(\tan \alpha+\frac{4}{\pi}\right)
$$

The static equilibrium in the $Z$ direction is as follows:

$$
G+Q_{1}-\left(2 T_{3}+2 C_{3}+T_{2}+C_{2}\right) \sin \alpha-T_{P}-C_{P}-Q_{2} \cos \alpha=0,
$$

where $G$ is the gravity of wedge ( $a b c d e f$ ); $Q_{3}, T_{3}$, and $C_{3}$ are the supporting force, sliding friction, and cohesive friction of wedge side ( $a d e$ ) and ( $b c f$ ), respectively; $Q_{2}, T_{2}$, and $C_{2}$ are the supporting force, sliding friction, and cohesive friction of the wedge inclined plane (abef), respectively; $T_{p}$ and $C_{p}$ are the wedge sliding and cohesive friction, respectively; and $\alpha$ is the included angle between the wedge and the horizontal level. 


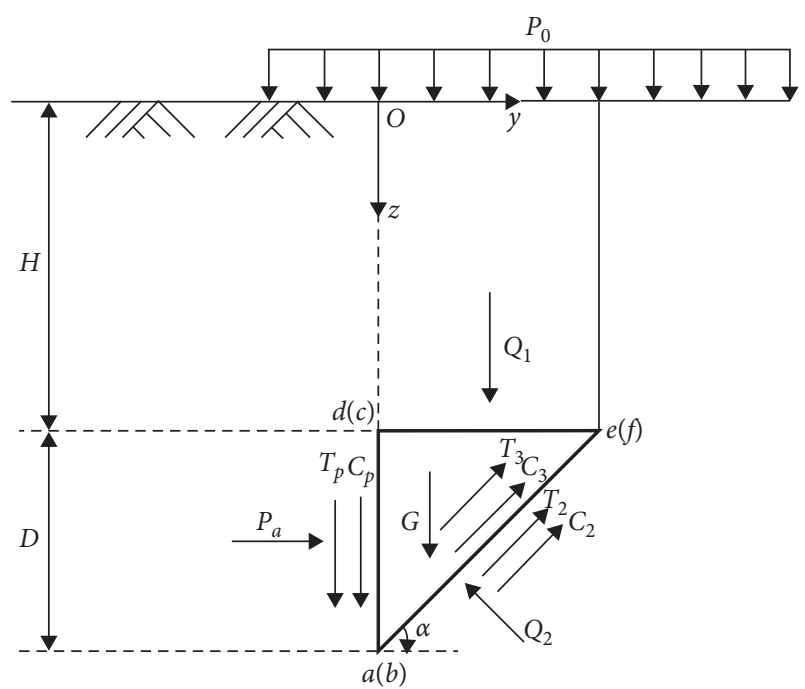

Figure 2: Force analysis of actively damaged wedge.

$$
\begin{aligned}
& T_{3}=Q_{3} \tan \varphi_{m}, \\
& T_{2}=Q_{2} \tan \varphi_{m}, \\
& T_{P}=P_{a} \tan \delta_{m} .
\end{aligned}
$$

From the static equilibrium in the $Y$ direction, it can be seen that

$$
P_{a}+\left(2 T_{3}+2 C_{3}+T_{2}+C_{2}\right) \cos \alpha-Q_{2} \sin \alpha=0,
$$

where $P_{a}$ is the shield support force to the excavation surface.

By substituting equations (10) and (11) into equation (12), the calculation equation of active support force of excavation surface can be acquired:

$$
\begin{aligned}
P_{a}= & \frac{-\left(2 Q_{3} \tan \varphi_{m}+2 C_{3}+C_{2}\right)\left[\sin \alpha \tan \left(\alpha-\varphi_{m}\right)+\cos \alpha\right]}{1+\tan \delta_{m} \tan \left(\alpha-\varphi_{m}\right)} \\
& +\frac{\left(G+Q_{1}-C_{P}\right) \tan \left(\alpha-\varphi_{m}\right)}{1+\tan \delta_{m} \tan \left(\alpha-\varphi_{m}\right)} .
\end{aligned}
$$

The value of the internal friction angles $\varphi_{0}$ and $\varphi_{m}$ and the external friction angles $\delta_{0}$ and $\delta_{m}$ can be obtained by equations (1)-(6), which are related to displacement ratio $W$. Other parameters are calculated as follows:

$$
\begin{aligned}
& C_{2}=\frac{c \pi D^{2}}{4 \sin \alpha}, \\
& C_{3}=c \frac{D^{2}}{2 \tan \alpha}, \\
& G=\frac{1}{2} \gamma B D^{2} \cot \alpha, \\
& C_{P}=\frac{c \pi D^{2}}{8} .
\end{aligned}
$$

Assuming that the support force and earth pressure are balanced during shield tunneling, the active support force at the center point of the excavation surface can be obtained as follows:

$$
P_{a}^{\prime}=\frac{4 P_{a}}{\pi D^{2}} .
$$

3.2.1. The Inclination Angle of Wedge Slope $\alpha$. Generally, the inclination angle of the sliding surface of the wedge can be assumed as $45^{\circ}+\varphi / 2$ for the active limit support force in the three-dimensional wedge model. The slope angle of the wedge-shaped sliding surface gradually decreases as the support force and the soil displacement reduce. Therefore, the inclination angle of wedge sliding surface is defined as

$$
\alpha=45^{\circ}+\varphi-\varphi_{m} / 2 \text {. }
$$

3.2.2. Overburden Earth Pressure $Q_{1}$. The calculation methods of overburden earth pressure include the proctor's earth pressure theory, the loose pressure estimation method proposed by Terzaghi (1923), and the standard calculation method. Among these, the loose earth pressure theory given by Terzaghi is extensively utilized because of its rationality. Therefore, the calculation of overburden earth pressure is acquired by

$$
Q_{1}=\sigma_{v}(H) A \text {. }
$$

3.2.3. Force on Both Sides of Wedge $Q_{3}$. The stress analysis of the wedge is shown in Figure 3. In the light of Rankine's theory, the expression of earth pressure at $z^{\prime}$ is as follows:

$$
\sigma_{h}\left(z^{\prime}\right)=K \sigma_{v 0}+K \gamma z^{\prime} .
$$

The force on both sides of the wedge $\left(Q_{3}\right)$ is

$$
Q_{3}=\int \sigma_{h}\left(z^{\prime}\right) \mathrm{d} A=\int \sigma_{h}\left(z^{\prime}\right) l\left(z^{\prime}\right) \mathrm{d} z^{\prime} .
$$

In equation (19),

$$
l\left(z^{\prime}\right)=D \cot \alpha-z^{\prime} \cot \alpha .
$$

Substituting equation (20) into equation (19), then

$$
Q_{3}=\int \sigma_{h}\left(z^{\prime}\right)\left(D \cot \alpha-z^{\prime} \cot \alpha\right) \mathrm{d} z^{\prime} .
$$

The integral of equation (21) leads to

$$
Q_{3}=\frac{K}{2} \sigma_{v 0} D^{2} \cot \alpha+\frac{1}{6} K \gamma D^{3} \cot \alpha .
$$

3.3. Calculation of Passive Support Force of Excavation Surface. Based on the three-dimensional wedge model, the failure pattern of the excavation surface is still assumed as a wedge, and the top of the wedge is changed into an inverted 


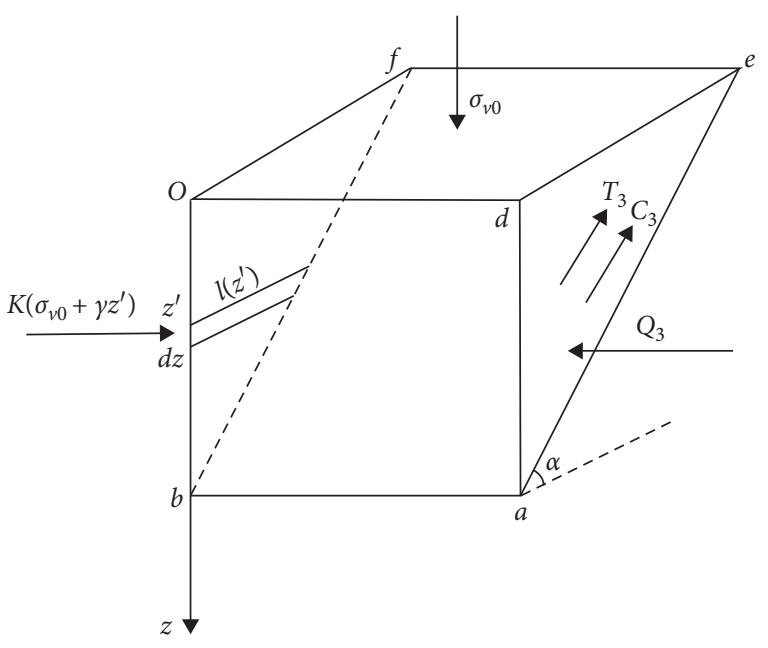

FIgURE 3: Force analysis of wedge.

prism. The stress analysis of the wedge in front of the excavation surface is indicated in Figure 4.

The calculation process of the passive support force is similar to that of the active support force. Therefore, in view of the equilibrium state in $y$ and $z$ directions, the total passive support force can be obtained as follows:

$$
\begin{aligned}
P_{p}= & \frac{\left(2 Q_{3} \tan \varphi_{m}+2 C_{3}+C_{2}\right)\left[\sin \beta \tan \left(\beta+\varphi_{m}\right)+\cos \beta\right]}{1-\tan \delta_{m} \tan \left(\beta+\varphi_{m}\right)} \\
& +\frac{\left(G_{1}+Q_{1}+C_{P}\right) \tan \left(\beta+\varphi_{m}\right)}{1-\tan \delta_{m} \tan \left(\beta+\varphi_{m}\right)} .
\end{aligned}
$$

In equation (23), the values of internal friction angles $\varphi_{0}$ and $\varphi_{m}$ and external friction angles $\delta_{0}$ and $\delta_{m}$ can be seen from equations (1) to (6), which are related to displacement ratio $\delta_{m}$; other parameters are calculated as follows:

$$
\begin{aligned}
C_{2} & =\frac{c \pi D^{2}}{4 \sin \beta}, \\
C_{3} & =\frac{c \pi D^{2}}{2 \tan \beta}, \\
G & =\frac{1}{2} B D^{2} \cot \beta, \\
Q_{3} & =\frac{\lambda \gamma(H+D / 2) D^{2}}{2 \tan \beta}, \\
T_{3} & =Q_{3} \tan \varphi_{m}, \\
C_{S} & =\frac{c \pi D^{2}}{8} .
\end{aligned}
$$

Similarly, the passive support force at the center point of the excavation surface can be obtained as follows:

$$
P_{p}^{\prime}=\frac{4 P_{p}}{\pi D^{2}}
$$

On the basis of the theory of displacement-based earth pressure in this paper, the inclination angle of the wedge sliding surface $(\beta)$ is calculated by

$$
\tan \beta=\tan \varphi_{m}\left[\sqrt{1+\cot \varphi_{m} \cot \left(\varphi_{m}+\delta_{m}\right)}-1\right] .
$$

The inclination angle of the inverted prism $(\omega)$ above the wedge is calculated by the angle of the sliding surface under the active failure model:

$$
\omega=\frac{\pi}{4}+\varphi-\varphi_{m} / 2
$$

Thus, the displacement-based lateral pressure coefficient is given by

$$
\lambda=\frac{1}{\sin \beta \cos \left(\beta+\varphi_{m}+\delta_{m}\right) / \cos \beta \cos \delta_{m} \sin \left(\beta-\varphi_{m}\right)+2 \tan \delta_{m} \tan \beta} .
$$

The stress analysis of the inverted prism above the wedge is shown in Figure 5.

The geometric parameters of the inverted prism are defined: the lower surface of the inverted prism or the upper wedge surface is $E$ in length, $B$ in width, and $A$ in the area; the upper surface of the inverted prism is $E^{\prime}, B^{\prime}$ in width, and $A^{\prime}$ in area; the side area of the inverted prism is $A_{1}$, and the volume of the inverted prism is $V$.

Based on the mechanical equilibrium of the inverted prism, the force $Q_{1}$ of the inverted wedge prism is obtained as follows:

$$
Q_{1}=Q_{5}+G_{1}+\left(T_{4}+C_{4}\right) \sin \omega,
$$

where $Q_{5}$ is the force of the soil above the inverted prism in the failure height; $T_{4}$ and $C_{4}$ are the sliding friction and cohesive friction of the inverted prism, respectively; and $G_{1}$ is the gravity of the inverted prism in the failure height of the soil.

The corresponding calculation equations are as follows:

$$
\begin{aligned}
& Q_{5}=\gamma(H-X) A^{\prime} \\
& T_{4}=\lambda \gamma A_{1}\left(H-\frac{X}{2}\right) \cos \omega \tan \varphi_{m} \\
& G_{1}=\gamma V \\
& C_{4}=c A_{1} .
\end{aligned}
$$

By substituting equation (30) into equation (29), the overburden earth pressure $Q_{1}$ can be obtained. 


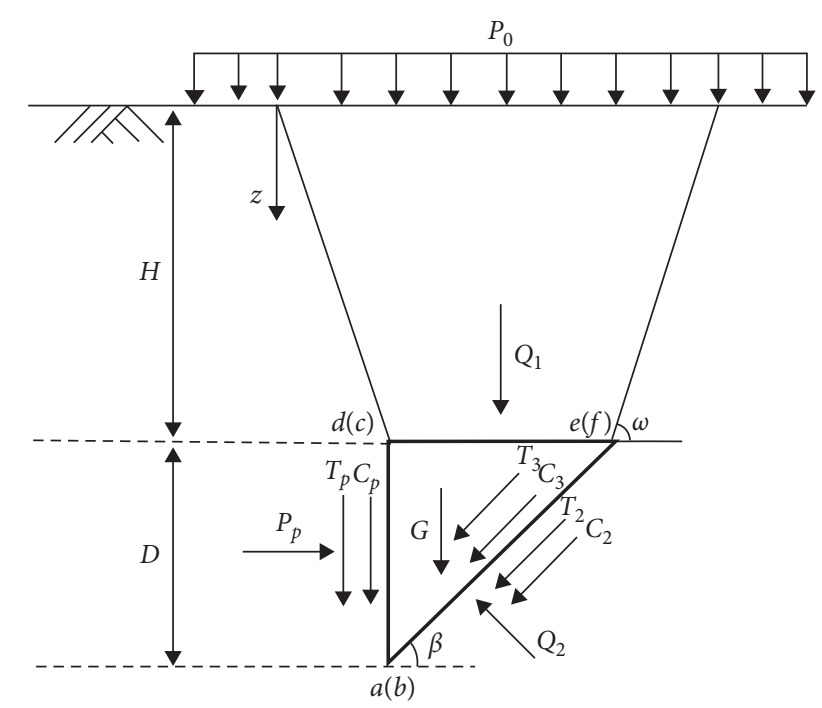

FIGURE 4: Force analysis of passively damaged wedge.

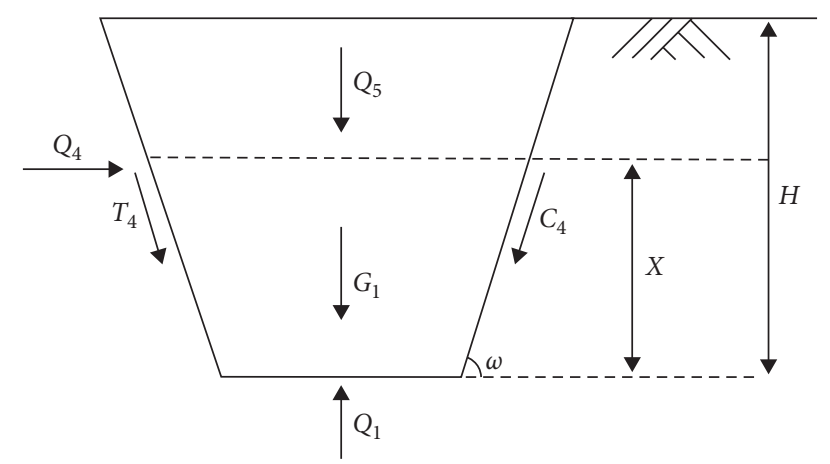

FIgURE 5: Stress analysis of chamfered cylinder.

\section{Comparison of the Proposed Model with Numerical Simulation}

4.1. Numerical Calculation and Parameters. A numerical calculation based on the program FLAC3D is used to verify the established theoretical model in this paper. The FLAC3D is a numerical simulation software based on the difference method (Itasca company, USA). The geometric model scale is $20 \times 30 \times 24 \mathrm{~m}$. Here, the diameter size of the tunnel section is $6 \mathrm{~m}$. Due to the symmetry of the geometric model, half of the models are selected for calculation (Figure 6). The model has a free surface, horizontal side direction constrained, and bottom fixed. As a typical example, for the tunnel model with buried depth ratio $H / D=1$, there are 66871 elements and 66920 nodes.

The shield segment is assumed to be made of C50 reinforced concrete. The thickness of the segment is $35 \mathrm{~cm}$ and is considered a linear elastic material. Mohr-Coulomb's yield criterion is used to describe the sandy soil layer. Shell element is used for the contact surface between segment and concrete, and the specific material parameters are shown in Table 1.

The sand soil layers with two buried depth ratios (i.e., $H / D=0.5$ and $H / D=1)$ and four internal friction angles (i.e., $\varphi=25^{\circ}, 30^{\circ}, 35^{\circ} 40^{\circ}$ ) are numerically simulated. Table 2 shows the calculation cases and conditions.

4.2. Influence of Shield Tunneling Displacement on Support Force. Case 1-Case 4 are taken as an example to obtain the influence of shield tunneling displacement on the active support force. The material calculation parameters and displacement ratio are substituted into equations (13) and (30), respectively, and the above same conditions and material parameters are numerically simulated. The results of theoretical calculation and numerical simulation are shown in Figure 7.

According to Figure 7 , the theoretical and numerical results are consistent and demonstrate that the active support force changes with an increased displacement ratio. When the ratio of internal friction angle to buried depth is certain, the active support force decreases with the displacement ratio increase. Moreover, the difference between theoretical and numerical simulation is between 0 and $5 \mathrm{kPa}$, and the error is minimal.

The same method is adopted to obtain the influence of shield tunneling displacement on the passive support force. The theoretical and numerical results shown in Figure 8 are consistent and represent the changing trend of passive support force with increasing displacement ratio. Figure 8 indicates that, as the internal friction angle and buried depth ratio are fixed, the passive support force increases with increasing the displacement ratio. Moreover, the divergence between the theoretical values and the numerical simulation results is between 0 and $0.1 \mathrm{MPa}$, and the error is also minor.

4.3. Comparison of Ultimate Support Force. Using equations (13) and (23), the active and passive ultimate supporting forces of the excavation surface under 8 cases are obtained. The calculation results are shown in Table 3.

The excavation surface support force is gradually increased or decreased with the same conditions and material parameters mentioned above until the center displacement of the tunnel excavation surface develops rapidly and reaches the limit state. The corresponding support force is selected as the limit support force calculated by numerical method. The ultimate support force calculated by theoretical and numerical methods is compared, as manifested in Figure 9.

From Figure 9, the changing trend of the ultimate support force with increasing the internal friction angle is consistent between the theoretical and numerical simulation under different buried depth ratio conditions. Therefore, the active limit support force decreases with increasing the internal friction angle, and on contrary, the passive limit support force increases. From another perspective, as the internal friction angle is fixed, the active and passive limit support forces increase with increasing the buried depth ratio. In addition, the difference between the theoretical and the numerical results is not significant. The differences between the active limit support force and the passive limit support force are 


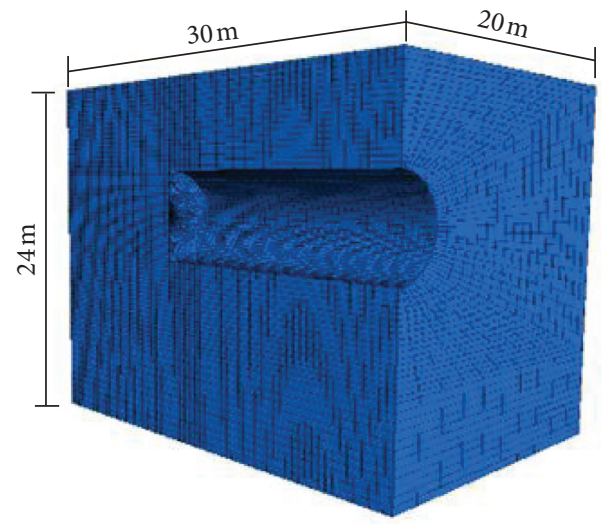

Figure 6: Numerical calculation model.

TABLE 1: Computational parameter.

\begin{tabular}{|c|c|c|c|c|c|}
\hline Materials & Elastic modulus (MPa) & Poisson's ratio & Density $\left(\mathrm{kg} / \mathrm{m}^{3}\right)$ & Cohesion $(\mathrm{kPa})$ & Tensile strength $(\mathrm{kPa})$ \\
\hline Soil & 20 & 0.35 & 1800 & 1 & 1 \\
\hline Shield segment & 30000 & 0.25 & & & \\
\hline
\end{tabular}

TABLE 2: Cases of numerical simulation.

\begin{tabular}{lcc}
\hline Case & $H / D$ & $\varphi\left(^{\circ}\right)$ \\
\hline 1 & 0.5 & 25 \\
2 & 0.5 & 30 \\
3 & 0.5 & 35 \\
4 & 0.5 & 40 \\
5 & 1 & 25 \\
6 & 1 & 30 \\
7 & 1 & 35 \\
8 & 1 & 40 \\
\hline
\end{tabular}

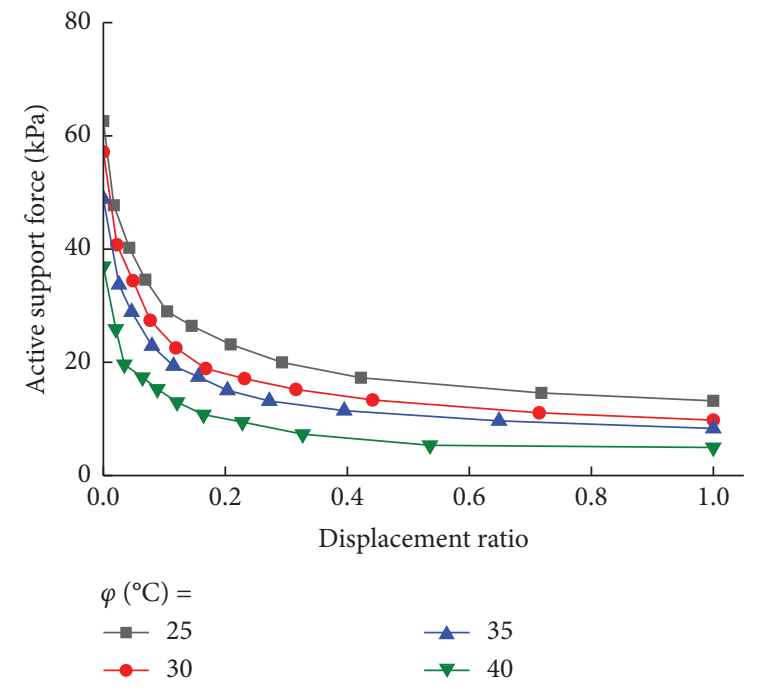

(a)

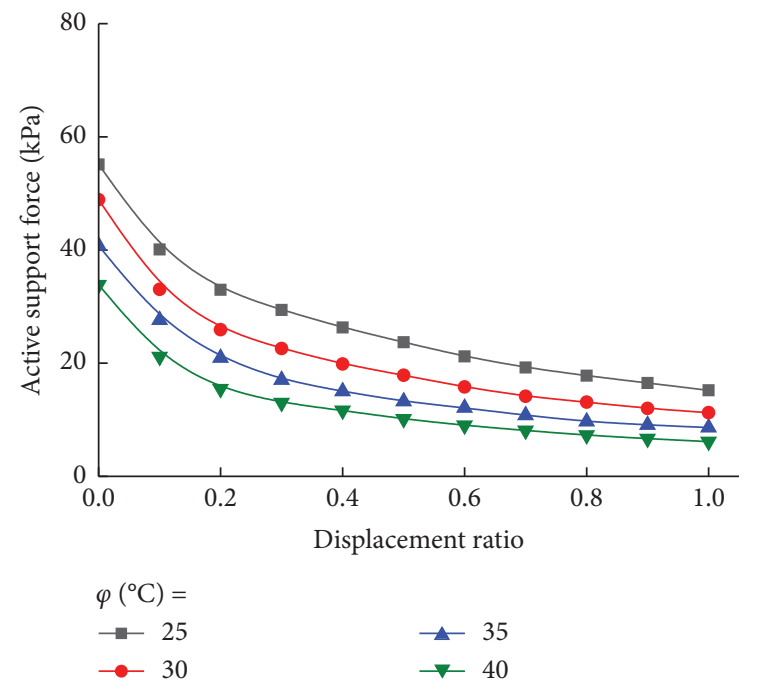

(b)

Figure 7: Comparison of the influence of shield driving displacement on active support force: (a) theoretical results and (b) numerical results. 


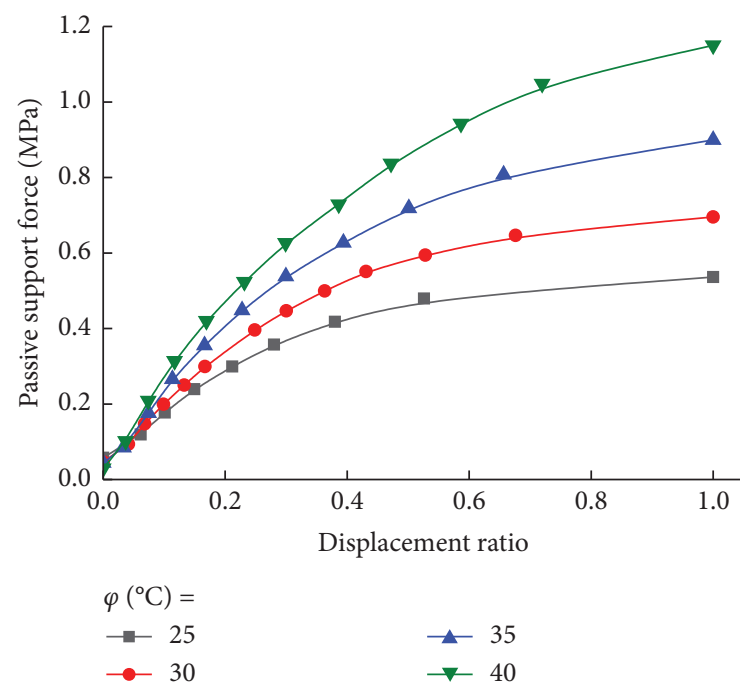

(a)

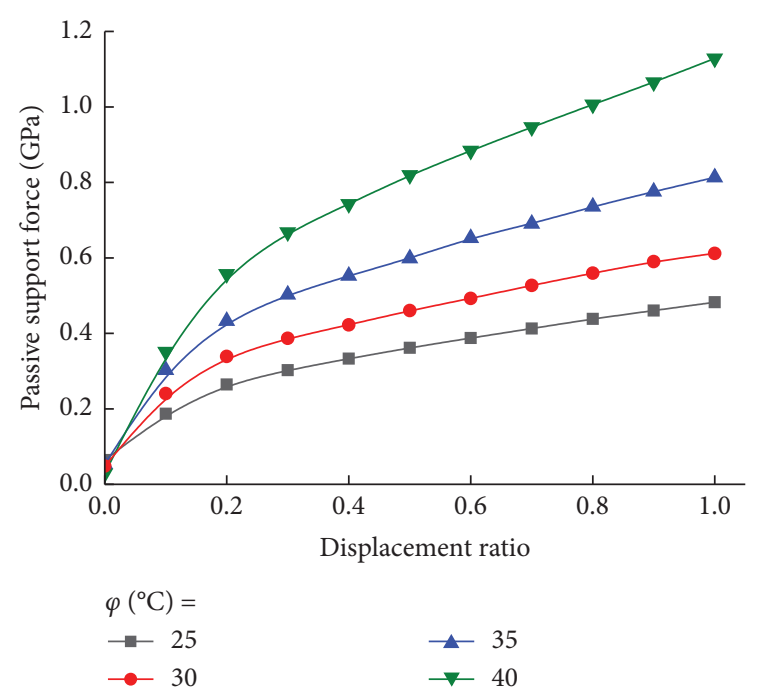

(b)

FIGURE 8: Comparison of the influence of shield driving displacement on the passive supporting force: (a) theoretical results and (b) numerical results.

TABLE 3: Theoretical results of the ultimate supporting force.

\begin{tabular}{lccc}
\hline$H / D$ & $\varphi\left(^{\circ}\right)$ & Active ultimate support force $(\mathrm{kPa})$ & Passive ultimate support force $(\mathrm{kPa})$ \\
\hline 0.5 & 25 & 14.51 & 480 \\
0.5 & 30 & 11.65 & 630 \\
0.5 & 35 & 8.4 & 820 \\
0.5 & 40 & 6.12 & 1120 \\
1 & 25 & 17.77 & 850 \\
1 & 30 & 12.56 & 950 \\
1 & 35 & 9.57 & 1420 \\
1 & 40 & 6.6 & 1880 \\
\hline
\end{tabular}

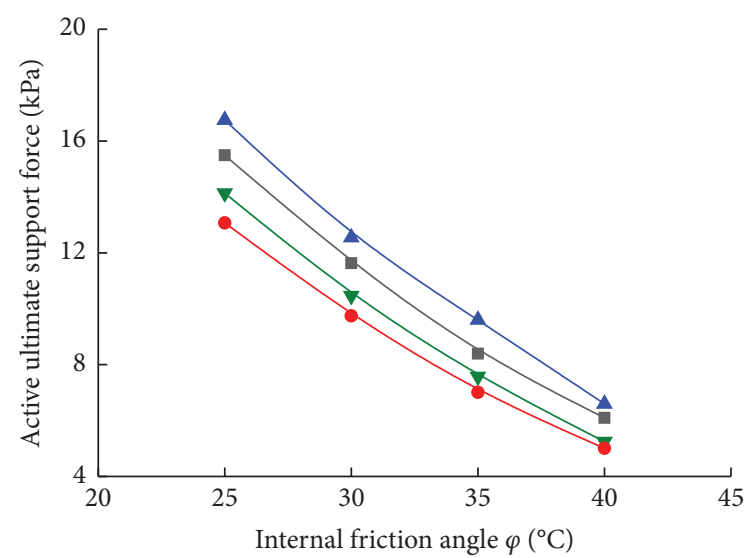

- Theoretical, $H / D=0.5$

$\rightarrow$ Numerical, $H / D=0.5$

$\_$Theoretical, $H / D=1.0$

$\rightarrow$ Numerical, $H / D=1.0$

(a)

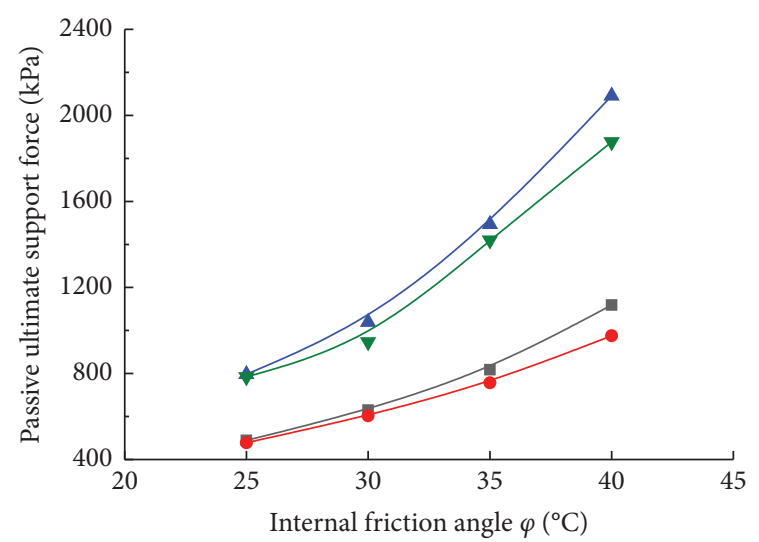

$\square$ Theoretical, $H / D=0.5$

$\rightarrow$ Numerical, $H / D=0.5$

$\leadsto$ Theoretical, $H / D=1.0$

$\rightarrow$ Numerical, $H / D=1.0$

FIGURE 9: Comparison of ultimate support force obtained from theoretical and numerical calculation: (a) active ultimate support force and (b) passive ultimate support force. 
$0-4 \mathrm{kPa}$ and $0-3 \mathrm{kPa}$, respectively, which is within the acceptable range proving the rationality of the theoretical equation.

\section{Conclusions}

Based on the three-dimensional wedge assumption, the relationship of the support force and the corresponding displacement on the excavation surface of the shield in the shallow sandy soil layer is derived using the displacement earth pressure and the plastic limit equilibrium theories.

When the ratio of internal friction angle to buried depth is certain, the active support force decreases with increasing the displacement ratio, while the passive support force decreases with increasing the displacement ratio. Moreover, the difference between the theoretical calculation and the numerical simulation is very small.

When the buried depth ratio is constant, the active ultimate support force decreases with increasing the internal friction angle, while the passive ultimate support force increases with increasing the internal friction angle. From another perspective, as the internal friction angle is fixed, the active and passive ultimate support forces increase with the rise in the buried depth ratio. Overall, the above analyses indicate the rationality of the proposed displacement-based calculation theory for predicting the support force.

\section{Data Availability}

The data used to support the findings of this study are available from the corresponding author upon request.

\section{Conflicts of Interest}

The authors declare that they have no conflicts of interest.

\section{Acknowledgments}

This work was supported by the National Natural Science Foundation of China (52078031).

\section{References}

[1] X. Hu, C. He, G. Walton, Y. Fang, and G. Dai, "Laboratory model test of EPB shield tunneling in a cobble-rich soil," Journal of Geotechnical and Geoenvironmental Engineering, vol. 146, no. 10, Article ID 04020112, 2020.

[2] B. Bai, D. Rao, T. Xu, and P. Chen, "SPH-FDM boundary for the analysis of thermal process in homogeneous media with a discontinuous interface," International Journal of Heat and Mass Transfer, vol. 117, pp. 517-526, 2018.

[3] L. Li, S. Sun, J. Wang, W. Yang, S. Song, and Z. Fang, "Experimental study of the precursor information of the water inrush in shield tunnels due to the proximity of a water-filled cave," International Journal of Rock Mechanics and Mining Sciences, vol. 130, Article ID 104320, 2020.

[4] B. Bai, T. Xu, Q. Nie, and P. Li, "Temperature-driven migration of heavy metal $\mathrm{Pb}^{2+}$ along with moisture movement in unsaturated soils," International Journal of Heat and Mass Transfer, vol. 153, Article ID 119573, 2020.
[5] L. Flessati and C. di Prisco, "Deep tunnel faces in cohesive soils under undrained conditions: application of a new design approach," European Journal of Environmental and Civil Engineering, vol. 51, Article ID 1785332, 2018.

[6] S. Zingg and G. Anagnostou, "Tunnel face stability and the effectiveness of advance drainage measures in water-bearing ground of non-uniform permeability," Rock Mechanics and Rock Engineering, vol. 51, no. 1, pp. 187-202, 2017.

[7] B. Bai, D. Rao, T. Chang, and Z. Guo, "A nonlinear attachment-detachment model with adsorption hysteresis for suspension-colloidal transport in porous media," Journal of Hydrology, vol. 578, Article ID 124080, 2019.

[8] K.-H. Park, J.-G. Lee, and A. Owatsiriwong, "Seepage force in a drained circular tunnel: an analytical approach," Canadian Geotechnical Journal, vol. 45, no. 3, pp. 432-436, 2008.

[9] T. Qiu, C. Liu, X. Zhong, and Y. Zhu, "Experimental research on the impact of temperature on the adhesion characteristics of soil-structure interface," Geofluids, vol. 2020, Article ID 6675576, 9 pages, 2020.

[10] B. Bai, L. Guo, and S. Han, "Pore pressure and consolidation of saturated silty clay induced by progressively heating/ cooling," Mechanics of Materials, vol. 75, pp. 84-94, 2014.

[11] B. Bai and Z. Su, "Thermal responses of saturated silty clay during repeated heating-cooling processes," Transport in Porous Media, vol. 93, no. 1, pp. 1-11, 2012.

[12] I.-M. Lee and S.-W. Nam, "The study of seepage forces acting on the tunnel lining and tunnel face in shallow tunnels," Tunnelling and Underground Space Technology, vol. 16, no. 1, pp. 31-40, 2001.

[13] I. Lee, S. Nam, and J. Ahn, "Effect of seepage forces on tunnel face stability," Canadian Geotechnical Journal, vol. 40, no. 2, pp. 342-350, 2002.

[14] B. Bai, H. Li, T. Xu, and X. Chen, "Analytical solutions for contaminant transport in a semi-infinite porous medium using the source function method," Computers and Geotechnics, vol. 69, pp. 114-123, 2015.

[15] D. Soubrin and H. Wong, "Tunnel face stability in frictional material: a new 3D failure mechanism," Comptes Rendus Mecanique, vol. 330, no. 7, pp. 513-519, 2002.

[16] P. A. Vermeer, P. G. Bonnier, and S. C. Mollen, "On a smart use of 3D-FEM in tunneling," in Proceedings of the 8th International Symposium on Numerical Models in Geomechanics, Rome, Italy, April 2002.

[17] X. Lü, S. Zeng, Y. Zhao, M. Huang, S. Ma, and Z. Zhang, "Physical model tests and discrete element simulation of shield tunnel face stability in anisotropic granular media," Acta Geotechnica, vol. 15, no. 10, pp. 3017-3026, 2020.

[18] C. Dai, H. Sui, and C. Ma, "Study on the ultimate supporting force of shield excavation face based on anisotropic strength theory," Applied Sciences, vol. 10, no. 15, p. 5222, 2020.

[19] X. Liang, F. Ye, A. Ouyang, X. Han, and X. Qin, "Theoretical analyses of the stability of excavation face of shield tunnel in Lanzhou metro crossing beneath the yellow river," International Journal of Geomechanics, vol. 20, no. 11, Article ID 04020200, 2020.

[20] B. Mi and Y. Xiang, "Analysis of the limit support pressure of a shallow shield tunnel in sandy soil considering the influence of seepage," Symmetry, vol. 12, no. 6, p. 1023, 2020.

[21] Y. Liang, Y. Xiao, and Y. Lin, "Pore water pressure responses in sand stratum during shield tunnelling: a case study," Advances in Civil Engineering, vol. 2020, Article ID 6139246, 9 pages, 2020.

[22] X.-Y. Wang, D.-J. Yuan, D.-L. Jin, and W.-L. Su, “Thermal and mechanical response of soil and tunnel during replacement of 
shield tail brush by freezing method," KSCE Journal of Civil Engineering, vol. 24, no. 5, pp. 1632-1640, 2020.

[23] B. Bai and X. Shi, "Experimental study on the consolidation of saturated silty clay subjected to cyclic thermal loading," Geomechanics and Engineering, vol. 12, no. 4, pp. 707-721, 2017.

[24] X. Li, T. Li, and L. Peng, "Elastoplastic two-surface model for unsaturated cohesive soils under cyclic loading," International Journal of Geomechanics, vol. 20, no. 8, Article ID 04020122, 2020.

[25] G. C. Yang and B. Bai, "Thermo-hydro-mechanical model for unsaturated clay soils based on granular solid hydrodynamics theory," International Journal of Geomechanics, vol. 19, no. 10, Article ID 04019115, 2019.

[26] B. Bai, Q. Nie, Y. Zhang, X. Wang, and W. Hu, "Cotransport of heavy metals and $\mathrm{SiO}_{2}$ particles at different temperatures by seepage," Journal of Hydrology, vol. 51, Article ID 125771, 2020.

[27] Y. Wang, Z. Li, H. Jing, Y. Li, and M. Wang, "Study on the seepage characteristics of deep buried tunnels under variable high-pressure water heads," Bulletin of Engineering Geology and the Environment, vol. 80, no. 2, pp. 1477-1487, 2021.

[28] Y. Wang, F. Chen, X. Li, X. Yin, and Y. Lei, "The variable-mass seepage law of broken porous rock: an experimental study," Geomatics, Natural Hazards and Risk, vol. 11, no. 1, pp. 1991-2005, 2020.

[29] Z. Zizka, B. Schoesser, M. Thewes, and T. Schanz, "Slurry shield tunneling: new methodology for simplified prediction of increased pore pressures resulting from slurry infiltration at the tunnel face under cyclic excavation processes," International Journal of Civil Engineering, vol. 17, no. 1, pp. 113-130, 2019.

[30] B. Bai, F. Long, D. Rao, and T. Xu, "The effect of temperature on the seepage transport of suspended particles in a porous medium," Hydrological Processes, vol. 31, no. 2, pp. 382-393, 2017.

[31] A. Hamrouni, D. Dias, and B. Sbartai, "Probability analysis of shallow circular tunnels in homogeneous soil using the surface response methodology optimized by a genetic algorithm," Tunnelling and Underground Space Technology, vol. 86, pp. 22-33, 2019.

[32] K. Terzaghi, "Record earth pressure testing machine," Engineering News Record, vol. 109, no. 29, pp. 365-369, 1932.

[33] M.-F. Chang, "Lateral earth pressures behind rotating walls," Canadian Geotechnical Journal, vol. 34, no. 4, pp. 498-509, 1997.

[34] J. Xu and Q. Pan, "Analysis of the upper limit of the shield tunnel excavation surface support force," Journal of Railway Science and Engineering, vol. 11, no. 4, p. 80, 2014.

[35] B. Bai, "Fluctuation responses of saturated porous media subjected to cyclic thermal loading," Computers and Geotechnics, vol. 33, no. 8, pp. 396-403, 2006.

[36] G. Mollon, D. Dias, and A.-H. Soubra, "Probabilistic analysis of pressurized tunnels against face stability using collocationbased stochastic response surface method," Journal of Geotechnical and Geoenvironmental Engineering, vol. 137, no. 4, pp. 385-397, 2011.

[37] L. Wang, K. Han, T. Xie, and J. Luo, "Calculation of limit support pressure for EPB shield tunnel face in water-rich sand," Symmetry, vol. 11, no. 9, p. 1102, 2019. 